\title{
PROBABILITY FROM A SOCIO-CULTURAL PERSPECTIVE
}

\author{
SASHI SHARMA \\ The University of Waikato \\ sashi@waikato.ac.nz
}

\begin{abstract}
There exists considerable and rich literature on students' misconceptions about probability; less attention has been paid to the development of students' probabilistic thinking in the classroom. Grounded in an analysis of the literature, this article offers a lesson sequence for developing students' probabilistic understanding. In particular, a context familiar to teachers-exploring compound events that occur in a game of chance-is presented, and it is demonstrated how the context can be used to explore the relationship between experimental and theoretical probabilities in a classroom setting. The approach integrates both the content and the language of probability and is grounded in socio-cultural theory.
\end{abstract}

Keywords: Statistics education research; Teaching probability; Socio-cultural theory; High-school students; Language issues

\section{INTRODUCTION}

"Life is a school of probability." (Bagehot, 1956, p. 421)

As the above quote suggests, probability pervades almost everything we do: To name only a few examples, probabilities related to side effects of medication, risks of household accidents, and environmental impacts regularly appear in the news media and in research reports (Gigerenzer \& Gray, 2011; Woolfson, 2012). The principles and concepts of probability are also used in analysing games of chance, genetics, and making weather predictions (Greer \& Mukhopadhyay, 2005).

Probability spans a number of disciplines, including physics, economics, and the sciences, because of the wide range of applicability of its principles and concepts. It provides the foundational theory for the development of statistics and is essential in understanding any inferential procedures used in this field. Generally speaking, probability offers a tool for modelling and simulating reality, which can provide a link between mathematics and the real world (Borovcnik, 2008; Greer \& Mukhopadhyay, 2005). Gal (2005) suggests that attention to real-world demands should be part of the considerations that guide what gets taught, assessed, and valued in the statistics classroom.

In recognition of the importance of probability in both school and out of school settings, there has been a movement in many countries to include probability at every level in the mathematics curriculum (Kazima, 2007; Nacarato \& Grando, 2014; Paul \& Hlanganipai, 2014; Watson, 2006). In New Zealand (Ministry of Education, 2007), probability is one of the three sub-strands in the mathematics curriculum and viewed as critical in the learning of mathematics and statistics. The use of meaningful contexts and drawing on students' experiences and understandings is recommended as a way of

Statistics Education Research Journal, 15(2), 126-144, http://iase-web.org/Publications.php?p=SERJ

(C) International Association for Statistical Education (IASE/ISI), November, 2016 
enhancing students' understanding of probability (Garfield \& Ben-Zvi, 2009; Ministry of Education, 2007; Watson, 2006).

Despite the importance of probability in everyday life and in school settings, a number of research studies (Amir \& Williams, 1999; Chiesi \& Primi, 2009; Fischbein \& Schnarch, 1997; Jones, Langrall, \& Mooney, 2007; Lecoutre, 1992; Rubel, 2007; Sharma, 2014; Watson, 2006; Zazkis \& Chernoff, 2008) from different theoretical perspectives and cultures show that students tend to hold certain beliefs about probability that negatively impact their learning. For instance, Borovenik (2008) found that misconceptions about probability can affect people's decisions in important situations, such as those involving medical tests, jury verdicts, and investments. Therefore, instruction in probability should provide experiences during which students have the opportunity to confront their misconceptions and to develop understandings based on probabilistic thinking. However, though there exists considerable literature on students' misconceptions in probability, less attention has been paid to the development of students' probabilistic thinking in the classroom (Jones et al., 2007; Nacarato \& Grando, 2014; Nilsson, 2013; Paul \& Hlanganipai, 2014; Zawojewski \& Shaughnessy, 2000).

At the same time, during the last two decades, there have been calls for a shift in the approach to the teaching and learning of probability in order to meet the needs of a knowledge society (Cobb \& McClain, 2004; National Council of Teachers of Mathematics, 2000). A major aspect of the reform is the move from traditional, teachercentred classrooms that focus on delivering content to classrooms where discourse and conceptual development are central (Cobb, 2007; Garfield \& Ben-Zvi, 2008; Van de Walle, Bay-Williams, Lovin, \& Karp, 2014). In particular, it is argued that students should be implicated to the greatest extent possible in explaining, providing evidence, finding or creating examples, generalising, analysing, making predictions, applying concepts, representing ideas in different ways, and articulating connections or relationships between the given topic and other ideas (Cobb \& McClain, 2004; Van de Walle et al., 2014). Teaching approaches that foster these learning goals may also engender in students a willingness to engage in challenging tasks and to take risks (Sullivan \& Mornane, 2014). These ideas resonate with the principles of socio-cultural theory, which will be discussed in Section 2.1.

This article attempts to address the issues discussed above by offering an open-ended lesson sequence for teaching probability. The approach integrates various conceptions of probability and is grounded in socio-cultural theory. The article consists of five major sections. This first section provides the theoretical background for the teaching sequence advocated in this article, discusses some characteristics of socio-cultural theory, and examines various approaches to probability that have relevance for teaching this topic. The second section summarizes research in probability education, in particular highlighting student misconceptions and potential language barriers. Section 3 reviews research on teaching probability. Section 4 provides a possible lesson sequence for exploring and developing probability ideas, which is also intended to link the concrete (experimental) and abstract (theoretical) notions of probability. Finally, the article concludes with a few reflections.

\section{THEORETICAL BACKGROUND}

\subsection{SOCIO-CULTURAL THEORY}

Socio-cultural theory derives its origins from the work of socio-cultural theorists such as Vygotsky (1978) and Wenger (1998), who suggest that learning should be considered 
more as a product of social, cultural, and political influences and less as an individual activity. Vygotsky (1978) argued that learning first occurs in the context of shared social activity known as the social or interpersonal plane, and is followed by development on the individual plane. Learning in these two planes can occur in any context, whether during mathematics lessons, in the workplace, or in the home. There is a strong emphasis in socio-cultural theory on social interactions, language, experience, collaborative learning environments, catering to cultural diversity, and meaningful contexts in the learning process, as opposed to a focus solely on the learner's cognitive abilities (Cobb, 2007). According to this theory, children's knowledge, ideas, and values develop through interactions with others; hence, language is seen as playing a central role in cognitive development.

Mediation is a key concept in Vygotsky's theory, which describes the shift from the social plane to the psychological plane (Wertsch, 1985). Vygotsky argued that higher mental processes are mediated by tools (i.e., technical tools, such as calculators) and signs (i.e., psychological tools, such as language). Learning takes place when these different forms of mediation create a transformation in mental functioning.

The notion of the zone of proximal development (ZPD) is another key feature of socio-cultural theory. Vygotsky (1978, p. 86) introduced the notion of the zone of proximal development as follows:

[The ZPD] is the difference between [a child's] actual development level as determined by independent problem solving and the level of potential development as determined through problem solving under adult guidance or in collaboration with more capable peers.

In other words, Vygotsky argued that intellectual development occurs within the ZPD of the child when assisted by a more knowledgeable individual. At the centre of the zone, the learner needs a high degree of assistance from a more experienced person in order to carry out the task. Such assistance could be provided during teaching in the form of guidance and/or collaboration. Over time, the outer limit of the ZPD is reached, when the "learner eventually becomes able to carry out what was previously a joint activity and can independently complete the task" (Cobb, 2007, p. 21). One implication of this theory is the idea that students learn most effectively when classroom conversation is within their individual zones of proximal development. Teachers can aim to target these zones to provide students with the right amount of challenge to avoid boredom on the one hand and anxiety on the other (when the challenge is beyond the students' capability).

To summarize the above, socio-cultural theory not only positions the learner as being actively engaged in seeking meaning during the learning process, but also suggests that the learner can be assisted by working with others who are more knowledgeable (Van de Walle, et al., 2014; Watson, 2006). This idea can be applied to the learning of probability. For example, when students are learning about experimental probability, teachers may have students collect data to explore the probability of various events, such as those that can be observed when flipping two coins. Students may initially think that two heads, two tails, and one head and one tail are equally likely outcomes (Lecourte, 1992; Watson, 2006) and, therefore, that each has a probability of $1 / 3$. A more knowledgeable person (a peer or the teacher) will know that if a large number of trials is performed the data will suggest that that the outcome "one head and one tail" actually has a 50 percent probability of occurring, and that creating a list of all possible outcomes will help students understand why the numerical probabilities of these outcomes are different. This more knowledgeable teacher or peer can draw students' attention to the critical idea that the possible outcomes in an experiment are related to probability. 


\subsection{APPROACHES TO PROBABILITY}

People think about probability using at least three different approaches: theoretical, experimental, and subjective. If students are to develop a meaningful understanding of probability, it is important to acknowledge these different approaches as well as to explore the connections between them and the different contexts in which one or the other may be most useful. Because the first two approaches in particular (theoretical and experimental) have relevance for this article, they are discussed in more detail below.

The theoretical approach to probability assumes that it is possible to represent the sample space (all possible outcomes) as a collection of outcomes with known probabilities. When the outcomes are equally likely, the probability can be determined by counting the number of favourable outcomes and dividing by the total number of outcomes in the sample space. This approach to probability enables one to calculate probabilities before any trials are performed. For example, the probability of rolling a six on a regular six-sided die is determined to be $1 / 6$, because this event represents one out of a total of six equally likely outcomes. One could also examine the symmetry of a regular six-sided die to estimate that the probability of rolling a six is $1 / 6$. In both cases, the theoretically derived probability is an estimate of the simple case of rolling a die. Although the outcomes of rolling a die or other chance games can be explained by theoretical probability, more complex situations in everyday life (e.g., weather events, accident risks, and epidemics) require other approaches. Even in some classroom situations, theoretical probability is impossible to calculate. For instance, when rolling an unfair die, the only way of estimating the actual probability of an event may be to perform an experiment with a large number of trials.

Experimental approaches to probability, in contrast, assume that the probability of a given event can be determined through experimentation. Experimental or empirical probability is said to be posterior, in that the probability of an event is determined from the observed relative frequency of that event over the course of several trials (Borovcnik, Bentz, \& Kapadia, 1991). Like theoretical probability, empirical probability also involves computing ratios, but in this case it is determined by dividing the number of times an event occurs by the total number of trials performed. As the number of trials increases, the experimental probability tends towards the theoretical probability of an event. By comparing inferences from their theoretical and empirical work, students can evaluate and modify their initial hypotheses.

From a practical point of view, the frequentist (experimental) approach does not provide the probability of an event when it is physically impossible to repeat an experiment a very large number of times. For example, it is impossible to conduct repeated trials to estimate the probability that one will live beyond 70 years or that one's house will be burglarized within a year. It is also difficult to decide how many trials are needed to obtain a good estimate for the probability of an event. Moreover, it is not possible to obtain a frequentist estimate of the probability of an event that only occurs one time under certain conditions. Another potential issue is the possibility of confusing models with reality. Indeed, in the view of Batanero and colleagues $(2005$, p. 23), "the most significant criticism of the frequentist definition of probability is the difficulty of confusing an abstract mathematical object with the empirical observed frequencies, which are experimentally obtained."

Although determining the theoretical probability of an event may appear to be straightforward, students often have considerable difficulty doing so. Some of these challenges are examined in the next section. 


\section{RESEARCH IN PROBABILITY EDUCATION}

\subsection{PREVIOUS STUDIES}

As mentioned earlier, a number of research studies from different theoretical perspectives and cultural contexts show that students tend to hold certain beliefs about probability that negatively impact their learning. Some common beliefs, biases, heuristics, and other issues that inhibit the learning of probability which are of relevance to this article are discussed next.

Equiprobability Lecoutre (1992) utilized several forms of a task that required college students to compare the probability of rolling a five and a six on two dice, in any order, with the probability of rolling two sixes. About half of the students in the sample indicated that these events are equally likely. Lecoutre called this phenomenon the "equiprobability bias": the tendency to view the random nature of the trials of an experiment as sufficient indication of equiprobable outcomes. The typical justification of such a response, as reported by Lecoutre, is that the two events are equiprobable because "it's all about chance." As Lecoutre found, the equiprobability bias tends to be highly resistant to change.

Fischbein, Nello, and Marino (1991) reported similar results among elementary and middle school students who responded to a problem involving two coins, and Zawojewski and Shaugnessy (2000, p. 237) reported similar findings among 12th graders who were asked the following question:

Suppose you are playing a carnival game that involves flipping two balanced coins simultaneously. To win the game you must obtain "heads" on both coins. What is your probability of winning the game?

Approximately $50 \%$ of the 12 th grade students in the study believed that there is a $50 \%$ chance of winning the game. According to Zawojewski and Shaughnessy (2000), an experimental approach can be used to convince students that such ideas need to be revised: in this case, as students simulate many trials of the game and see that they win approximately $25 \%$ of the time, they may become convinced that the chance of winning is not $50 \%$.

One-step bias Lysoe (2008) reported that one common strategy in solving problems with certain compound events is to transform a two-step problem into a simple event and then use the uniform model. Lysoe called this approach the one-step orientated heuristic. As an illustration, consider the following problem and argument (Lysoe, 2008, p. 14):

Anna has three red, two green and one blue pencil in her pen case. She asks Maria to pick out two pencils without looking. Anna thinks that the probability that both of the pencils are red is $1 / 5$ but Maria thinks that the probability is $1 / 3$. Does either of them have the correct answer?

I agree with Maria. [Argument:] There are a total of 6 pencils and Maria picks out 2 pencils; this leads to the probability $2 / 6=1 / 3$ for red pencils.

In the above problem, each individual pencil has a probability of $1 / 6$ to be picked. Lysoe (2008) writes that the student seems to have selected two of the three red pencils and considered the two red pencils as a unit and added the probabilities. In other words, it appears that the student has reformulated the two-stage experiment into one-stage task, hence reducing the sample space into two events; picking the two red pencils or not. 
Beliefs Research (Amir \& Williams, 1999; Sharma, 2014) shows that some students believe that the outcomes of certain events depend on a force that is beyond their control. Amir and Williams (1999), for instance, interviewed thirty-eight 11 to 12-year-old students in their first year of secondary school about their conceptions of chance and luck, their beliefs and attitudes, and their reasoning about probability. Some pupils in the study reported that they thought that God controls everything that happens in the world; others believed that God chooses which events to control, while and still others believed that God does not control anything or does not exist. Other reported beliefs in the study were directly related to coins and dice: For instance, some students reported believing that a coin landing on "tails" is luckier than landing on "heads."

Zimmermann and Jones (2002) studied high school students' thinking and beliefs by presenting them with problems involving two-dimensional probability simulations. One that emerged from the study was the finding that some students, although to different degrees, seem to believe that simulation cannot be used to model a real-world probability problem. Another study showed that if students come to class with strongly held beliefs about probability, seeing visualisations of repeated simulation process and resulting distribution may not facilitate understanding or cause them to update these beliefs (Ireland \& Watson, 2009).

Language issues Probability is a complex topic that can be interpreted descriptively using words such as "impossible," "never," "unlikely," and so on. However, the way in which these terms are used in the mathematical field of probability sometimes differs from the way in which they are used in everyday life (Paul \& Hlanganipai, 2014; Kazima, 2007; Lesser \& Winsor, 2009; Nacarato \& Grando, 2014; Watson, 2006), which may hinder students' communication when learning about probability. As an illustration, consider the following task, described in Sharma (2014, p. 109):

Meena and Ronit have some marbles. Meena is 10 years old. In her box, there are 10 white marbles and 20 black ones. Ronit is only 8 years old. In her box there are 20 white marbles and 60 black ones. They play a game. The winner is the child who pulls out a white marble first. If both take out a white marble at the same time then no one is the winner and the game has to go on. Ronit claims that Meena has a greater chance of pulling out a white marble because she is older, and cleverer.

What is your opinion about this?

A few students in the study missed the point of the question, focusing rather on whether the game was fair. This is reflected in the comment made by one of the students (Sharma, 2014, p. 111):

This is not a fair game; for this, the game should be played by same aged people and there should be equal number of marbles in the box.

Another student explained why it was fair that Ronit, the younger child, had more marbles (Sharma, 2014, p. 111).

At my home I got three brothers so when my father gets two apples, then he gives one whole apple to my smaller brother and us two brothers, we get half each.

In the statistical context, "fair" means that each player has the same theoretical chance of winning a game (Watson, 2006). However, in everyday register, "fair" has different meanings, such as, "unbiased" or "in accordance with the rules of equity." The first quote appears to have in-school beliefs about fairness while at the same time holding contradictory beliefs about the notion in out-of-school situations. Typically, the first denotation of a term that comes to mind is its everyday use of the term (Lavy \& Mashiach-Eizenberg, 2009), which presents difficulties when learning probability. English language learners may face an even greater challenge when learning probability, 
for they must simultaneously learn and work with terms that have both "ordinary" and mathematical meanings (Lesser \& Winsor, 2009).

\subsection{RESEARCH ON TEACHING PROBABILITY}

There are different views on how to best teach probability so that students leaving school are able to accurately interpret probabilities in a wide range of situations (Gurbuz, Erdem, \& Firat, 2014; Jones et al., 2007; Kapadia, 2009; Nilsson, 2013; Paul \& Hlanganipai, 2014). Some of these views are based on elements of socio-cultural theory (Section 2.1) and the different approaches to probability (Section 2.3).

As discussed earlier, students have many misconceptions about probability (Garfield \& Ben-Zvi, 2008; Jones et al., 2007; Nilsson, 2013). Additionally, they may have difficulty using statistical terms with precision. To address these issues, Gürbüz, Erdem, and Firat (2014) conducted a cross-sectional study with grade 6-8 students. Pre- and posttests results were compared after an intervention. As part of the learning activities, students made predictions, collected, collated, and compared data in groups. The group discussions provided opportunities for interaction and support. Students could ask questions and receive direct and immediate feedback in a safe learning environment. The researchers reported that the collaborative environment and activity-based tasks had a positive impact on student learning.

In another study, Prediger and Rolka (2009) observed a group of 12-year-olds playing a game of chance with tokens that moved forward on a playing board according to the results of a die roll. The icosahedral die used in the game had more red sides than sides of any other colour, and therefore favoured the red token. Observations such as "there are more red sides on the die" and "the red token wins more often" were voiced by some students. The fierce discussion among the children led to a jointly developed strategy. The authors suggest that the verbal communication seemed to generate a better understanding of the effectiveness of their tactics, which might not have occurred if they had simply observed the game. The studies suggest that collaborative learning aids the development of probability concepts.

Nilsson (2013) distinguished two methodological and analytical directions based on the bi-directional relationship between theoretical and empirical probability:

Mapping direction: Theoretical probability $\Rightarrow$ Experiment $\Rightarrow$ Empirical probability

Inference direction: Experiment $\Rightarrow$ Empirical probability $\Rightarrow$ Theoretical probability

Nilsson argued that the direction used depends largely on whether the underlying sample space is known by or hidden from students. In cases where the theoretical model of a random generator (dice, coins, spinners) is known from sample space considerations, students can be challenged to reflect on how the model corresponds to the distribution of outcomes that the random generator produces. In cases where the theoretical probability is hidden or impossible to determine by sample space considerations, teaching can focus on developing students' abilities to make informal statistical inferences about empirical probabilities and to connect experimental information to theoretical probability.

The ability to generate all of the possible outcomes of a random process is essential in developing a theoretical model for the probabilities of the various outcomes of the process. In their study, Horvath and Lehrer (1998) demonstrated how children in grade 2 (aged 7-8) and grades 4-5 (aged 9-11) are able to develop an understanding of how a theoretical sample space maps to a corresponding experimental data distribution after being introduced to a notational system for organizing the sample space. However, when the results of an experiment differed from their predictions, the grade 2 students turned to the data rather than to the theoretical sample space for making new predictions. That is, in 
a natural manner, they changed from the mapping direction to the inference direction. The older students, on the other hand, tended to rely on the sample space for predicting how the data would be distributed. The study stresses the importance of teaching students to systematically structure the sample space in order to enhance their capacity to understand and predict empirical distributions.

Research by Chernoff and Zazkis (2011) demonstrates students' difficulties in listing all possible outcomes of a random process and in understanding how the underlying sample space regulates the probabilities of a random phenomenon. Zazkis and Chernoff (2008) suggest that students who wrestle with counter examples that enable them to personally experience cognitive conflict are more likely to experience new learning than those who are simply presented with expert opinions about concepts related to probability.

Garfield and Ben-Zvi (2009) advocate an instructional sequence that begins with the presentation of a meaningful task or problem and continues with an invitation to solve that problem in multiple ways, which leads to the sharing, justifying, and discussing of those problem solving strategies in small or large groups. The roles assumed by the teacher and the students and the environments associated with this type of teaching differ from "traditional" approaches (Cobb \& McClain, 2004; Garfield \& Ben-Zvi, 2009). In particular, the role of the teacher is to guide and support students in achieving the desired outcomes. Traditional approaches tend to be teacher-centred, and concepts or methods are transmitted by the teacher. Mathematics ideas are not negotiated and attention is hardly paid to context or student prior knowledge.

A strategy that aligns with elements of the socio-cultural theory of learning and which is often used in science education is called "Predict, Observe and Explain." The strategy helps teachers identify students' zones of proximal development and target these zones to provide the right amount of challenge. It can also be used in teaching probability for identifying students' beliefs, prior knowledge, and thought processes, generating discussion, and motivating students to explore the relevant concepts (Joyce, 2006). After the prediction stage, surprising events create conditions where students may begin to reexamine their personal theories about probability. The strategy is based on the following principles:

- Unless students are asked to predict first what will happen during an experiment, they may not observe carefully.

- Writing down predictions motivates students to find the answer.

- Asking students to explain the reasons for their predictions allows the teacher to identify the students' beliefs and theories about a given concept. This can be useful for uncovering misconceptions or building on the understandings that students already have.

- Explaining and evaluating their own predictions and listening to others' predictions helps students to begin evaluating learning and constructing new meanings.

The research and theories discussed in this and previous sections informed the development of the open-ended lesson sequence described in the next section, which can be used to introduce probability concepts to high-school, middle school, and primary school students. The activity offers a meaningful context in which students can collect their own data and derive both experimental and theoretical probabilities. Younger students can solve the problem intuitively and informally through experimentation, whereas older students can delve deeper into the problem and look for patterns that may help them derive a theoretical model. The lesson sequence exhibits a range of characteristics of rich mathematical activities (Breyfogle \& Williams, 2008; Sullivan \& 
Mornane, 2014) and includes suggestions for adaptations. Breyfogle and Williams claim that a rich mathematics activity makes connection to children's prior knowledge and experiences, is set in a meaningful context, promotes discussion, and can be adapted. The sequences described below include all these criteria.

\section{A POSSIBLE LESSON SEQUENCE TO EXPLORE THE FAIRNESS OF A DICE ROLLING GAME}

The lesson sequence described below, grounded in socio-cultural theory, is designed to confront student misconceptions about probability so as to allow them to recognize the limitations of their intuition and the advantages of experimentation and mathematical theory. The sequence starts with a problem, rather than with mathematical theory or procedure, and the progression is from the empirical to the theoretical. The students first make predictions about the fairness of a game, conduct an experiment, and finally compare their predictions with the results of the experiment. It is important that students use tools such as technology and work collaboratively in groups or pairs, so that they are engaged in authentic conversation and interactions. Data is to be collected and analysed systematically to facilitate comparisons between predictions and experimental results.

The key ideas embedded in the lesson sequence presented below relate to curricular objectives (Ministry of Education, 2007) that advocate the linking of theoretical probability to experimental probability. It is evident that probability does not exist in a language-free vacuum. This means that when teaching students, teachers must not only be looking to teach statistics in and of itself, but recognize their dual role as statistics teachers and language teachers (Brown, Cadt, \& Taylor, 2009; Lesser \& Winsor, 2009). The sequence below that follows integrates strategies for teaching both probability and language. The sequence that follows integrates strategies for teaching both probability and language.

Problem The teacher engages the students by posing a question that is set in a meaningful context. The following problem will be used to provide a context for the ideas this section:

Esha and Sarah decide to play a dice rolling game. They take turns rolling two fair

dice and calculating the difference (larger number minus the smaller number) of the numbers rolled. If the difference is 0,1 , or 2, Esha wins, and if the difference is 3, 4 or 5, Sarah wins. Is this game fair? Explain your thinking.

The teacher should write the problem on the board and ask a student to read it. Then, the teacher should guide the class in a discussion about what information is given and what is required of them. The ideas discussed should be recorded on the whiteboard to help students with language difficulties. Alternatively, the teacher may introduce this task a few days before the lesson, collect students' responses, and examine what the responses reveal about their current level of understanding. This will give the teacher the opportunity to identify difficulties in advance of the lesson, which may enable him or her to help students more effectively during the next phase.

In this context, "fair" means that each player has the same theoretical chance of winning the game. (It is assumed that the dice being used to play the game are themselves fair.) Some students may have in-school beliefs about the notion of fairness while at the same time holding contradictory beliefs about this notion in out-of-school situations (Watson, 2006). The teacher could use the graphic organiser given in Figure 1 to clarify and distinguish the statistical meaning from its use in everyday language. Students can peer edit and evaluate one another's responses. 


\begin{tabular}{|l|l|}
\hline Statistical meaning & Other meaning(s) \\
\hline Picture/Image & Picture/Image \\
\hline
\end{tabular}

Figure 1. Graphic organiser to distinguish statistical meaning from other meanings

Making prediction The process of making predictions encourages students to think about the problem at hand and may reveal their misconceptions. Later, dissonance may be created between their predictions and the experimental results, encouraging the students to discard their misconceptions (Ireland \& Watson, 2009).

During this phase, students are given time to think individually about whether the game is fair and to write down their predictions and reasoning. Then, in pairs, students discuss their ideas and try to explain to each other why they chose the answers they did. The students have the opportunity to revise their predictions if they wish.

The teacher should circulate around the room and observe how students approach the task (e.g., whether they are drawing diagrams, working with probabilities, or simply writing a description). As they work on the task, the teacher should listen to their reasoning carefully and note any misconceptions that arise for later discussion with the whole class.

Expected student responses In the situation described above, the probabilities of winning are dependent on the rules of the game. Combining simple events such as rolling two dice and finding the difference usually creates a much more complex sample space than the original event. A single fair die has equiprobable outcomes, whereas outcomes involving the difference of two fair dice are not equally likely. However, as discussed in Section 3.1, students may hold the misconception that symmetrical objects such as coins and dice always produce outcomes that are equally likely (Lecourte, 1992). A few students may also demonstrate the one-stage bias in their reasoning (see Section 3.1; Lysoe, 2008), and others may think that some numbers are inherently luckier than others and thus more likely to come up (Amir \& Williams, 1999; Sharma, 2014). The latter belief would imply that a six-sided die is not fair. If students do hold this belief - that is, that the different numbers on a die have different chances of coming up-a discussion of fairness of the dice rolling game described above is likely to be challenging. In this case, the teacher may need to introduce another activity which encourages students to examine these ideas before going on to the next phase.

Playing the game Students play the game approximately 20 times with a partner and tally the results in a frequency table (Figures $2 \mathrm{a}$ and $2 \mathrm{~b}$ provide two different possibilities).

\begin{tabular}{|l|l|l|}
\hline Outcome & Tally & Frequency \\
\hline Esha wins & & \\
\hline Sarah wins & & \\
\hline
\end{tabular}

Figure 2a. Frequency Table 


\begin{tabular}{|l|l|l|}
\hline Roll Number & Esha wins & Sarah wins \\
\hline & & \\
\hline $\begin{array}{l}\text { Total number of } \\
\text { wins }\end{array}$ & & \\
\hline
\end{tabular}

Figure 2b. Frequency Table

After collecting the data, students record their responses to the following questions and then discuss them with another group.

\section{Focus questions}

- Considering your results, do you think the game is fair? Why or why not?

- If you wanted to win this game, which player would you choose to be? Explain your answer.

- If you played the game 30 more times, would the results be the same as or different from the first 20 times you played? If they would be different, how?

The teacher may need to provide some sentence starters to help students write their responses: for example, "From the table, it can be seen that ... because ..."

Expected student responses Some students will notice that the game is not fair since as one of the two players wins more times than the other, and will consequently change their minds about the fairness of the game. However, some of the students playing the role of Esha may say that they can see nothing wrong with the game. The teacher should tell them that everyone is going to play again, but that this time, all of the students will switch roles (i.e., those playing the role of Esha will play the role of Sarah, and vice versa). Some students will almost certainly object to this suggestion.

Some students may physically examine the dice. Others will hold on to the belief that one particular number is luckier than the others. Some might reason that there are six possible outcomes (differences of $0,1,2,3,4$, or 5) and that because three have been assigned to each player, the game is fair.

Planning explorations During this phase, students plan how they will gather more data.

The teacher should discuss the notion of sample size and suggest justifications for why the sample size matters. As a class, the students discuss what kind of experiments they could carry out to test their predictions. These experiments could involve physical or computer simulations. There needs to be some discussion about how a die should be rolled, as it is important that the students roll the dice in the same manner for each trial. The teacher should have the students make suggestions about how they will record their results. One possibility is given below in Figure 3.

\begin{tabular}{|l|l|l|}
\hline Outcome & $\begin{array}{l}\text { Frequency of occurrence } \\
\text { (tally) }\end{array}$ & $\begin{array}{l}\text { Relative frequency, or } \\
\text { experimental probability }\end{array}$ \\
\hline $0,1,2$ & & \\
\hline $3,4,5$ & & \\
\hline Totals & & \\
\hline
\end{tabular}

Figure 3. Possible data recording sheet 


\section{Focus questions}

- What data will we collect?

- How will we collect this data?

- How are we going to record this information?

Data collection and analysis In small groups, data is collected and recorded. Next, all of the group results are collated on the whiteboard and analysed. Experimental results are compared with students' initial ideas, leading to the realization that Esha wins more often than Sarah.

\section{Focus questions}

- Which differences are possible?

- Which differences were common?

- What is the probability of each difference?

Expected student responses Some students may have difficulty working with decimals and converting between fractions and decimals, in which case the teacher may need to review concepts related to place value. Some will recognize, if they didn't do so during the previous round of trials, that the game is not fair because one of the two players wins more often, and may consequently change their minds about the fairness of the game.

Each group could graph their results on posters, which can then be displayed at the front of the room. This is a powerful way to compare group results, because students can visually identify similarities and differences between the data sets which may not be apparent from simply reading the tables of collected data. The teacher may need to discuss graphing conventions, such as giving the graph a title and labelling the axes, so as to help students communicate their findings to others clearly.

\section{Focus question}

- What is the shape of the plotted data?

The students can use their own language to describe the shapes of the graphs, after which the teacher can introduce more precise language: symmetrical, sloped to the left, sloped to the right, uniform, non-uniform. The students match these words to their graphs.

Introducing the theoretical model In groups, students analyse the game to determine why Esha wins more often than Sarah. To answer this question, students need to enumerate the sample space in a systematic way. They can propose their own methods for listing the possibilities. Some possible approaches are listed next.

In Figure 4, the students first list all of the possible outcomes of rolling two dice.

\begin{tabular}{|l|l|l|l|l|l|}
\hline 1,1 & 1,2 & 1,3 & 1,4 & 1,5 & 1,6 \\
\hline 2,1 & 2,2 & 2,3 & 2,4 & 2,5 & \\
\hline
\end{tabular}

Figure 4. List of all possible differences when rolling two dice

Note that 1,2 and 2,1 represent different outcomes, but will give the same difference. One-way to help students understand this is to use two dice of different colours. 
Students could also draw a table listing all possible differences (Figure 5) and use it to find the number of ways of obtaining each one (Figure 6). Both methods reveal 36 possible combinations, 24 of which represent a win for Esha and 12 of which represent a win for Sarah.

\begin{tabular}{|c|c|c|c|c|c|c|c|}
\hline & \multicolumn{7}{|c|}{ DICE 1} \\
\hline \multirow{7}{*}{ 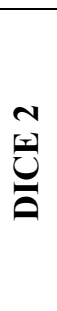 } & & 1 & 2 & 3 & 4 & 5 & 6 \\
\hline & 1 & 0 & 1 & 2 & 3 & 4 & 5 \\
\hline & 2 & 1 & 0 & 1 & 2 & 3 & 4 \\
\hline & 3 & 2 & 1 & 0 & 1 & 2 & 3 \\
\hline & 4 & 3 & 2 & 1 & 0 & 1 & 2 \\
\hline & 5 & 4 & 3 & 2 & 1 & 0 & 1 \\
\hline & 6 & 5 & 4 & 3 & 2 & 1 & 0 \\
\hline
\end{tabular}

Figure 5. All possible differences when rolling two dice

\begin{tabular}{|l|c|c|c|c|c|c|}
\hline Difference & 0 & 1 & 2 & 3 & 4 & 5 \\
\hline $\begin{array}{l}\text { Number of } \\
\text { ways to } \\
\text { obtain }\end{array}$ & 6 & 10 & 8 & 6 & 4 & 2 \\
\hline Who wins? & Esha & Esha & Esha & Sarah & Sarah & Sarah \\
\hline
\end{tabular}

Figure 6. Number of ways of obtaining each difference

Alternatively, a tree diagram can be drawn to find all of the possibilities, although this method could be a bit cumbersome.

Once the students have enumerated the sample space, the probability of each student winning the game can be calculated and the responses to prompts, such as the focus questions that follow. Students could compare their graphs (experimental data) with a graph similar to that which appears in Figure 7.

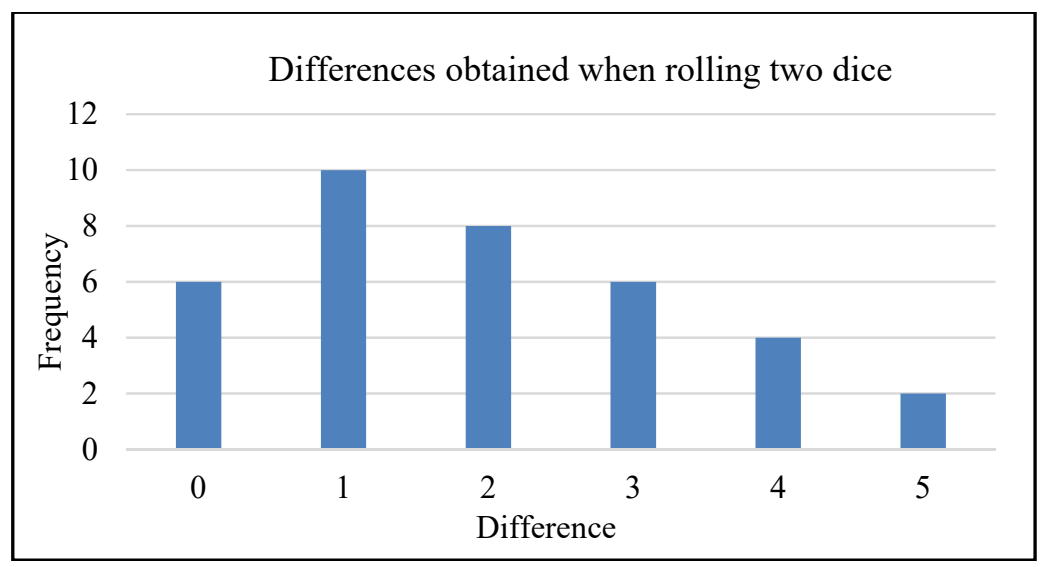

Figure 7. Graph of expected outcomes

\section{Focus questions}

- How do your experimental results compare with your theoretical probabilities? 
- Explain why they might differ.

- Discuss how knowing the probabilities helps you understand why the game is unfair.

- What are the relative advantages and disadvantages of experimental versus theoretical approaches to finding probabilities?

- What is the expected frequency of (say) a difference of four if you roll the two dice 72 times? 144 times?

- How can we change the rules so that each player has the same chance of winning?

- What would the distribution for a completely fair game look like?

Expected student responses Students might reason that the 36 outcomes listed in Figure 6 are equally likely. Although this is true, the differences are not equally likely: For example, comparing the outcomes of obtaining a difference of 4 and 5 reveals that there are four ways of getting a difference 4 and only two ways of getting a difference 5 . In other words, there are four outcomes favourable to the desired event (getting a 4) out of all of the possible outcomes (36), which gives a probability of 4/36 or 1/9 of getting a difference of 4 . Some students might recognise that the probabilities associated with the differences are hierarchically ordered, with the probability of getting a difference of 1 being the greatest, followed by 2 , then 0 or 3 , and so on.

There are many different ways of devising a fair game. One is to say that Esha wins if the difference is 0, 2 or 4 and Sarah wins if it is 1,3, or 5. Another is to say that Esha wins if the difference is 1 or 2 and Sarah wins otherwise.

Assessment After the wrap-up discussion, students may be asked to complete a brief assessment, providing the teacher with additional feedback about their learning during the lesson sequence. For example, the teacher may ask the students to decide whether the following statement is true or false and to write down reasons to support their answer:

Rolling a sum of three with two fair dice is twice as likely as rolling a sum of two.

Possible extension Students could be asked to design a fair game (where each player has the same chance of winning) and to test out their theoretical model experimentally. The teacher could also introduce other activities involving random generators, such as spinners and containers holding coloured blocks, to help students to transfer the concepts embedded in the lesson to other situations. For instance, students could be given a graph of results obtained from drawing different coloured blocks (e.g., red, yellow, green, and blue) 100 times with replacement from a bucket and asked to estimate the number of blocks of each colour that would produce the given graph. Data displays can help students understand the bi-directional connection between theoretical and empirical probabilities.

The teacher could also extend the activity by discussing the topic of expected value. In games of chance, a game is said to be fair if the price paid to enter the game is equal to the expected winnings. The gain or loss is the difference between the entry fee and the winnings. If the expected gain from the game is 0 , the game is fair. Although examples, such as the one following often appear in real life situations, expected values are taught procedurally at senior levels in school.

You're at a carnival and you see the following game: For \$2, you can roll a standard six-sided die. If the number showing is a six, you win $\$ 10$. Otherwise, you win nothing. Is this a fair game? 
In order to understand the notion of expected value, students need opportunities to develop their understandings through empirical investigations. In other words, students should be actively involved in hands-on experiments that motivate them and help them construct sound understandings.

\section{REFLECTIONS}

Many interesting questions that can be posed in the classroom can be addressed through the type of lesson sequence presented here. However, teachers should not expect one or two experiments to have a substantial impact on students' beliefs about probability. Some studies show that misconceptions about chance may continue to be held throughout life (Sharma, 2014; Watson, 2006). However, probabilistic thinking can be developed slowly and systematically in appropriate learning environments through carefully designed sequences of activities that challenge students to explore, make conjectures, and evaluate their reasoning.

School curricula need to acknowledge the two aspects of probabilistic thinking (i.e., experimental and theoretical), and the connections between the two should be reinforced over and over again. It is true that in some cases, it is not appropriate to introduce an experiment to find relative frequencies before suggesting a theoretical model based on, say, geometry or the enumeration of all possible outcomes. However, with the availability of computers, graphing calculators, and other tools for simulation, leaving out the datacollection phase is no longer an option. Hands-on simulation, as well as software simulation packages, can be used to explore the nature of probability distributions in many problem situations, which also gives students the opportunity to recognize and describe variability in data.

The inclusion of games in probability lessons can be particularly motivating for middle school students, as research suggests that the social element of learning is critical to students in this age group (Attard, 2012). However, it should be noted that the level of engagement may be related to aspects of the game such as competition, rather than the mathematics itself. For sustained engagement with games, there needs to be reflection about the mathematics involved and some challenge in terms of the probability content.

It has long been recognized that if we are to become critical citizens in our modern, technological society, we need to be able to estimate the probability of given outcomes of random processes based on the observed frequencies of the outcomes (Jones et al., 2007). However, there are also times when we must estimate the likelihood of an event when it is practically impossible to produce empirical evidence of its relative frequency. In such cases, we must be able to make predictions based on the composition of the random generator, although we must be careful to avoid the equiprobability bias. These two approaches to modeling probability support an approach to teaching the topic that aims to develop an understanding of both theoretical and empirical probabilities and, in particular, the connections and relationships between them (Nilsson, 2009; Van de Walle et al., 2014; Watson, 2006).

The ubiquity of computers and graphing calculators makes the teaching approach advocated in this article well suited to today's classrooms by making it easy to perform simulations in probability and statistics. However, although simulations can act as an intermediary between real events and theoretical models, it is important to understand that simulations may not support students' learning in all cases, especially if students hold strong beliefs about probability that contradict the simulation results. Giving students the opportunity to make predictions before running the simulations, and then to compare these predictions with the observed results, may help to remedy this issue. 
By providing a means of measuring the uncertainty that is omnipresent in our everyday lives, the principles and concepts of probability support students in becoming critical citizens of modern society. To achieve the goal of probability literacy for our students, our task as teachers is to provide appropriate learning environments which challenge students to make predictions, explore, and evaluate their reasoning (Garfield \& Ben-Zvi, 2008). The lesson sequence described in this article can challenge students in just such a way.

\section{REFERENCES}

Amir, G., \& Williams, J. (1999). Cultural influences on children's probabilistic thinking. Journal of Mathematical Behavior, 18(10), 85-107.

Attard, C. (2012). Engagement with mathematics: What does it mean and what does it look like? Australian Primary Mathematics Classroom, 17(1), 9-13.

Bagehot, W. (1956). Probability. In J. R. Newman (Ed.), The world of mathematics (pp. 421-455). New York, NY; Simon and Schuster. Retrieved from https://www.google.co.nz/?gws_rd=ssl\#q=life + is $+\mathrm{a}+$ school + of + probability

Batanero, C., Henry, M., \& Parzysz, B. (2005). The nature of chance and probability. In G. A. Jones (Ed.), Exploring probability in school: Challenges for teaching and learning (pp. 15-37). New York, NY: Springer.

Bay-Williams, J. M., \& Herrera, S. (2007). Is "just good teaching" enough to support the learning of English language learners? Insights from sociocultural learning theory. In W. G. Martin, M. E, Strutchens, \& P. C. Elliott (Eds.), The learning of mathematics. Sixty-ninth yearbook (pp. 43-63). Reston, VA: National Council of Teachers of Mathematics.

Borovcnik, M. (2008). Research and development in the teaching and learning of probability: A report on the topic study group 13 at ICME 11, Monterrey, Mexico. July 6-13, 2008.

Borovenik, M., Bentz, H.-J., \& Kapadia, R. (1991). A probabilistic perspective. In R. Kapadia \& M. Borovcnik (Eds.), Chance encounters: probability in education (pp. 27-71). Dordrecht, The Netherlands: Springer.

Breyfogle, L., \& Williams, L. (2008). Designing and implementing worthwhile tasks. Teaching Children Mathematics, 15(5), 276-280.

Brown, C. L., Cady, J. A., \& Taylor, P. M. (2009). Problem solving and the English language learner. Mathematics Teaching in the Middle School, 14(9), 532-539.

Chernoff, E. J., \& Zazkis, R. (2011). From personal to conventional probabilities: From sample set to sample space. Educational Studies in Mathematics, 77(1), 15-33.

Chiesi, F., \& Primi, C. (2009). Recency effects in primary-age children and college students. International Electronic Journal of Mathematics Education, 4(3), 259-274.

Cobb, P. (2007). Putting philosophy to work: Coping with multiple theoretical perspectives. In F. K. Lester (Ed.), Second handbook of research on mathematics reaching and learning (pp. 3-38). Charlotte, NC: Information Age Education.

Cobb, P., \& McClain, K. (2004). Principles of instructional design for supporting the development of students' statistical reasoning. In D. Ben-Zvi \& J. B.Garfield (Eds.), The challenge of developing statistical literacy, reasoning, and thinking (pp. 375395). Dordrecht, The Netherlands: Kluwer.

Fischbein, E., Nello, M. S., \& Marino, M. S. (1991). Factors affecting probabilistic judgements in children and adolescents. Educational Studies in Mathematics, 22, $523-549$. 
Fischbein, E., \& Schnarch, D. (1997). The evolution with age of probabilistic, intuitively based misconceptions. Journal for Research in Mathematics Education, 28, 96-105.

Gal, I. (2005). Towards "probability literacy" for all citizens: Building blocks and instructional dilemmas. In G. A. Jones (Ed.), Exploring probability in school: Challenges for teaching and learning (pp. 39-63). New York, NY: Springer.

Garfield, J. B., \& Ben-Zvi, D. (2008). Preparing school teachers to develop students' statistical reasoning. In C. Batanero, G. Burrill, C. Reading \& A. Rossman (Eds.), Joint ICMI/IASE study: Teaching statistics in school mathematics, challenges for teaching and teacher education. Proceedings of the ICMI Study 18 and the 2008 IASE Roundtable Conference, Monterrey, Mexico, July, 2008.

Garfield, J. B., \& Ben-Zvi, D. (2009). Helping students develop statistical reasoning: Implementing a statistical reasoning learning environment. Teaching Statistics, 31(30), 72-77.

Gigerenzer, G., \& Gray, M. (2011). Better patients. Better doctors. Better decisions. Envisioning health care 2020. Cambridge, England: MIT Press.

Greer, G., \& Mukhopadhyay, S. (2005). Teaching and learning the mathematization of uncertainty: Historical, cultural, social and political contexts. In G. A. Jones (Ed.), Exploring probability in school: Challenges for teaching and learning (pp. 297-324). New York, NY: Springer.

Gürbüz, R., Erdem, E., \& Firat, S. (2014). The effect of activity-based teaching on remedying the probability-related misconceptions: A cross-age comparison. Creative Education, 5(1), 18-30.

Horvath, J., \& Lehrer, R. (1998). A model-based perspective on the development of children's understandings of chance and uncertainty. In S. P. Lajoie (Ed.), Reflections on statistics (pp. 121-148). Mahwah, NJ: Erlbaum.

Ireland, S., \& Watson, J. (2009). Building a connection between experimental and theoretical aspects of probability. International Electronic Journal of Mathematics Education, 4(3), 339-370.

Jones, G. A., Langrall, C. W., \& Mooney, E. S. (2007). Research in probability: Responding to classroom realities. In F. K. Lester Jr. (Ed.), Second handbook of research on mathematics teaching and learning (pp. 909-955). Reston, VA: National Council of Teachers of Mathematics.

Joyce, C. (2006). Predict, observe, explain (POE). Retrieved from http://arb.nzcer.org.nz/strategies/poe.php

Kapadia, R. (2009). Chance encounters - 20 years later. Fundamental ideas in teaching probability at school level. International Electronic Journal of Mathematics Education, 4(3), 371-386.

Kazima, M. (2007). Malawian students meaning for probability vocabulary. Educational Studies in Mathematics, 64, 169-189.

Lavy, I., \& Mashiach-Eizenberg, M. (2009). The interplay between spoken language and informal definitions of statistical concepts. Journal of Statistics Education, 17(1). Retrieved from http://ww2.amstat.org/publications/jse/v17n1/lavy.html

Lecoutre, M. (1992). Cognitive models and problem spaces in purely random situations. Educational Studies in Mathematics, 23, 557-568.

Lesser, L., \& Winsor, M. (2009). English language learners in introductory statistics: Lessons learned from an exploratory case study of two-pre service teachers. Statistics Education Research Journal, 8(2), 5-32.

Lysoe, K. O. (2008). Strengths and limitations of informal conceptions in introductory probability courses for future lower secondary teachers. In M. Borovenik \& D. Pratt 
(Chairs), Research and development in the teaching and learning of probability Topic Study Group 13 at ICME 11, Monterrey, México.

Ministry of Education. (2007). The New Zealand curriculum. Wellington, New Zealand: Learning Media.

Nacarato, A. M., \& Grando, R. C. (2014). The role of language in building probabilistic thinking. Statistics Education Research Journal, 13(2), 93-103

National Council of Teachers of Mathematics (NCTM). (2000). Communication. In Principles and standards for school mathematics (pp.1-6). Reston, VA: Author.

Nilsson, P. (2013). Experimentation in probability teaching and learning. In E. J. Chernoff \& B. S. Sriraman (Eds.), Probabilistic thinking: Presenting plural perspectives (pp. 509-532). New York, NY: Springer.

Nilsson, P. (2009). Conceptual variation and coordination in probability reasoning. The Journal of Mathematical Behavior, 29(4), 247-261.

Paul, M., \& Hlanganipai, N. (2014). The nature of misconceptions and cognitive obstacles faced by secondary school mathematics students in understanding probability: A case study of selected Polokwane secondary schools. Mathematical Journal of Social Sciences, 5(8), 446-455.

Prediger, S., \& Rolka, K. (2009). Using betting games for initiating conceptual change. Asian Journal of Educational Research, and Synergy, 11, 61-71.

Rubel, L. H. (2007). Middle school and high school students' probabilistic reasoning on coin tasks. Journal for Research in Mathematics Education, 38(5), 531-556.

Sharma, S. (2014). Influence of culture on high school students' understanding of statistics: A Fijian perspective. Statistics Education Research Journal, 13(2), 104117.

Sullivan, P., \& Mornane, A. (2014). Exploring teachers' use of and students' reactions to challenging mathematics tasks. Mathematics Education Research Journal, 26(2), 193-214.

Van de Walle, J. A., Bay-Williams, J. M., Lovin, L., \& Karp, K. S. (2014). Teaching student-centered mathematics: Developmentally appropriate instruction for grades 6-8 (2nd ed.) Boston, MA: Pearson Education.

Vygotsky, L. (1978). Mind in society: The development of higher psychological processes. Cambridge, MA: Harvard University Press.

Watson, J. M. (2006). Statistical literacy at school: Growth and goals. Mahwah, NJ: Lawrence Erlbaum.

Wenger, E. (1998). Communities of practice learning, meaning and identity. Cambridge, England: Cambridge University Press.

Wertsch, J. V. (1985). Vygotsky and the social formation of mind. Cambridge, MA: Harvard University Press.

Woolfson, M. (2012). Everyday probability and statistics: Health, elections, gambling and war. London, England: Imperial College Press.

Zawojewski, J. S., \& Shaughnessy, J. M. (2000). Data and chance. In E. A. Silver \& P. A. Kenney (Eds.), Results from the Seventh Assessment of Educational Progress (pp. 235-268). Reston: VA: National Council of Teachers of Mathematics.

Zazkis, R., \& Chernoff, E. (2008). What makes a counterexample exemplary? Educational Studies in Mathematics, 68(3), 195-208.

Zimmermann, G. M., \& Jones, G. A. (2002). Probability simulation: What meaning does it have for high school students? Canadian Journal of Science, Mathematics and Technology Education, 2(2), 221-236. 
SASHI SHARMA

Te Kura Toi Tangata Faculty of Education The University of Waikato

Hamilton

New Zealand 